\title{
Criação/Música
}




\section{Um poema e duas canções}

\section{DOMÉNICO BARBIERI}

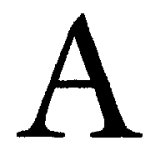

consagrada poetisa e teatróloga paulista Renata Pallottini tem três de suas poesias musicadas por Camargo Guarnieri: Saudade, em 1967; Oferta (Pallottini, 1952), em 1967 e 1977; e Poema Interior, em 1977. As primeiras estáo reunidas em Duas canfốes de Renata (Ministério das Relaçóes Exteriores, 1977); quanto à última, com este título, Pallottini năo conseguiu localizá-la na obra do maestro (1).

É útil relembrar que entre as características da denominada canção - ou, talvez mais precisamente, Lied -, além da linha melódica concordante com valores métricos, rítmicos, acentuaçóes do texto (Bartolotto, 1962) e, ainda mais, fiel à mensagem literária, o acompanhamento pianístico comenta, sublinha e, enfim, confere clima musical coerente ao texto poético (2).

Habitualmente, texto, linha melódica e acompanhamento pianístico atingem uma culminância psicológico-musical, isto é, um clímax, depois do qual, comumente, a canção se encaminha para o final. Diz melhor Bartolotto: "Se alcuni versi hanno su gli altri un eccesso di peso, fonico o semantico (e nei raggiungimenti massimi le due cose vanno insierme) ecco che um improviso allargando, un, annotazione espressiva i dinamica accordano la frase musicale su quel climax" (3).

Camargo Guarnieri, a quem Francisco Mignone se referiu como "...o mais perfeito e completo dos nossos músicos..." (OESP, 1983), é indiscutivelmente primoroso autor no difícil gênero do lied. Alinha até 1977, em seu Catálogo de Obras (Ministério de Educação e Cultura, 1977), o apreciável número de 191 cançóes para canto e piano. Cumpre ressaltar que a qualidade e o refinamento dessas obras sobrepujam, destacadamente, a quantidade. Várias estáo reunidas em importantes ciclos, dos quais se destacam: Quatro Poemas de Macunaima (1931); Treze Cançōes de Amor (1936-37); Para Acordar Teu Coração (1971); Cinco Poemas de Alice (1954); e Poemas da Negra (1957). 
Vamos nos ater à poesia Oferta, de Pallottini:

Hei de te dar sempre um pouco

Do que em mim é ser contente

E a minha felicidade

Vai de mãos dadas contigo.

Náo sou capaz de ter nada

Que não te dê de presente

Meus sorrisos têm o gosto

Dos olhos do meu amigo.

Trata-se de texto sintético, extremamente bem elaborado e de aguda sensibilidade, do qual se destaca brilhante figura de efeito sonoro - assonância (Goldstein, 1989) - no verso "Que náo te dê de presente..." . Ressaltamos que, dado o caráter sintético do poema, torna-se difícil distinguir semanticamente o trecho onde ocorreria o clímax. Em vista da assonância, já referida, julgamos estar nos referidos versos (Não sou capaz...).

À versão primeira de Oferta (Camargo Guarnieri, 1967), datada de Cascais em 1967, dedicada à cantora Edmar Ferretti, foi dado o caráter com alegria. Inicia-se em compasso $2 / 4$, que se modifica no decorrer da peça para 3/4 e 5/8. De um total de trinta e quatro compassos, os dois primeiros são dedicados à introdução; a melodia é ascendente e o canto se estende do $3^{\circ}$ ao $13^{\circ}$, havendo comentário pelo piano entre o $14^{\circ}$ e o $17^{\circ}$ compassos. A seguir, o canto é retomado e permanece até o final da canção, quando repete o último verso ("Dos olhos do meu amigo" ). A cançáo é monotemática e pode ser definida como de forma $A-A$, sendo que em $A^{\prime}$ há, apenas, pequenas modificaçóes no acompanhamento. A repetiçáo do último verso parece atuar como uma coda.

Acreditamos que o clímax poético musical é alcançado entre os compassos 18 e 23, quando o poema diz: "Năo sou capaz de ter nada que não te dê de presente...". O canto atinge a nota mais aguda na sílaba que do verso citado, ao mesmo tempo que a melodia se apresenta com maior expressividade. Leve imperfeição na transcriçăo da letra é observada no compasso 12: "(vai) de mão dadas (contigo)". No acompanhamento pianístico, muito bem realizado, nota-se apreciável trabalho contrapontístico e, ainda, engenhosos agrupamentos rítmicos. Este lied teve sua estréia em Sorocaba, em 1968, pela soprano Edmar Ferretti, com o autor ao piano (M.E.C., 1977).

Dez anos após, Guarnieri, tomando novamente contato com este poema, e esquecido de tê-lo musicado anteriormente - segundo comen- 
tário informal que nos foi feito pelo próprio compositor, há algum tempo -, empreende a feitura de um novo lied (Camargo Guarnieri, 1985).

A que chamaremos de segunda versäo (Camargo Guarnieri, 1977) foi composta em São Paulo, datada de 14 de maio de 1977, sem dedicatória, com o caráter calmo. Escrita em compasso 2/2, apresenta uma única mudança, para $3 / 2$, no compasso número 5 . A necessidade de alteraçóes do ritmo musical, impostas pelas modificaçóes do ritmo poético, resolve-se, nesta versão, pelo emprego freqüente das quiálteras.

Há uma introduçáo de quatro compassos; o canto, de melodia ascendente, percorre os compassos de 5 a 9,12 a 17 e 24 a 33, que é o último desta canção. Por sua vez, o piano exibe pontes e comentários nos compassos 10, 11 e de 18 a 23.

A escrita pianística é mais simples que a da versão primeira, ainda que o contraponto nos pareça mais rico, com saltos expressivos e ainda mais belos. Obviamente, são freqüientes as quiálteras no contracanto. Freqüentes, nesta versão, deformaçóes harmônicas, tanto no canto como no acompanhamento.

O trecho em que o poema diz "... a minha felicidade vai de mãos dadas contigo..." - compassos 12 a 16 - inicia-se com um salto de oitava (nona mi) no canto, juntamente com a indicação muito expressivo. Devemos considerar situado nesta parte o clímax da cançáo, devido a nota mais aguda e salto de oitava no canto, expressividade da linha melódica e, por fim, explicitada pela notação muito expressivo.

Os versos (" não sou capaz...") estendem-se dos compassos 24 a 27, e na versáo de 1967 foram considerados como clímax; nesta segunda versão, ainda que se inicie com salto de oitava no canto (nota ré ), não possui qualquer notação levando a concluir que o autor tenha conferido maior peso musical a este trecho. A forma composicional, nesta versão, também é A-A'.

Estas peças musicais, compostas há $25 \mathrm{e}$ há 30 anos, permanecem manuscritas, demonstrando o descaso, historicamente presente e geometricamente progressivo, que avilta nossos valores culturais.

A análise destas duas canções, advindas de um mesmo poema e elaboradas pelo compositor, esquecido da primeira versão composta anos antes, permite concluir que os produtos resultantes mantêm as mesmas características quanto à prosódia, ritmo musical e poético e, mesmo quanto ao alcance do clímax, ainda que possa existir alguma dúvida ou diferença no referente à sua colocação. Em resumo, ambas 
mantêm as características rítmico-psicológicas intrínsecas ao binômio poesia-música.

\section{Notas}

1 Renata Pallottini - Informafáo Pessoal, 1991. A escritora refere existir Pocma Anterior, publicado em Acalanto. É possível ter havido erro quanto ao nome, ou de impressão, ou então Guarnieri teria modificado o título - o que seria pouco provável.

2 Isto dentro dos limites do que se possa considerar coerente, visto não ser possível descrever, de maneira exclusivamente musical, idéias literárias, sentimentos, emoçóes etc.

3 Se alguns versos possuem peso maior, fônico ou semântico (e nos encontros mais enfáticos as duas coisas ocorrem simultaneamente), eis que um súbito allargado, uma anotaçāo expressiva ou dinâmica encaminham a frase musical àquele clímax.

\section{Referências bibliográficas}

BARTOLOTTO, Mario. Introduzione al lied romantico. Ed. G. Ricordi, 1962, p. 116.

CAMARGO GUARNIERI, M. Comunicafäo pessoal,1991. . Comunicação pessoal, por volta de 1985.

1977.

- Oferta - para canto e piano, com poesia de Renata Pallottini. Manuscrito,

GOLDSTEIN, Norma. Versos, sons, ritmos. 5a ed., São Paulo, Ática, 1989, p. 51.

MIGNONE, Francisco. Entrevista a Beatriz Marinho. O Estado de S.Paulo - caderno Cultura, 12 jun. 1983, p. 8-9.

MINISTÉRIO DAS RELAÇŌES EXTERIORES. Camargo Guarnieri - Catalogo de Obras, 1977.

PALLOTTINI, Renata. Acrlanto. Ediçāo do autor, sem indicaçăo de página, 1952.

Domênico Barbieri é compositor e professor da Faculdade de Ciências Farmacêuticas da USP. Peças de sua autoria foram executadas sob a regência dos maestros Camargo Guarnieri e Ronaldo Bologna.

O autor agradece as sugestōes de Renata Pallotini e do compositor Nilson Lombardi. 


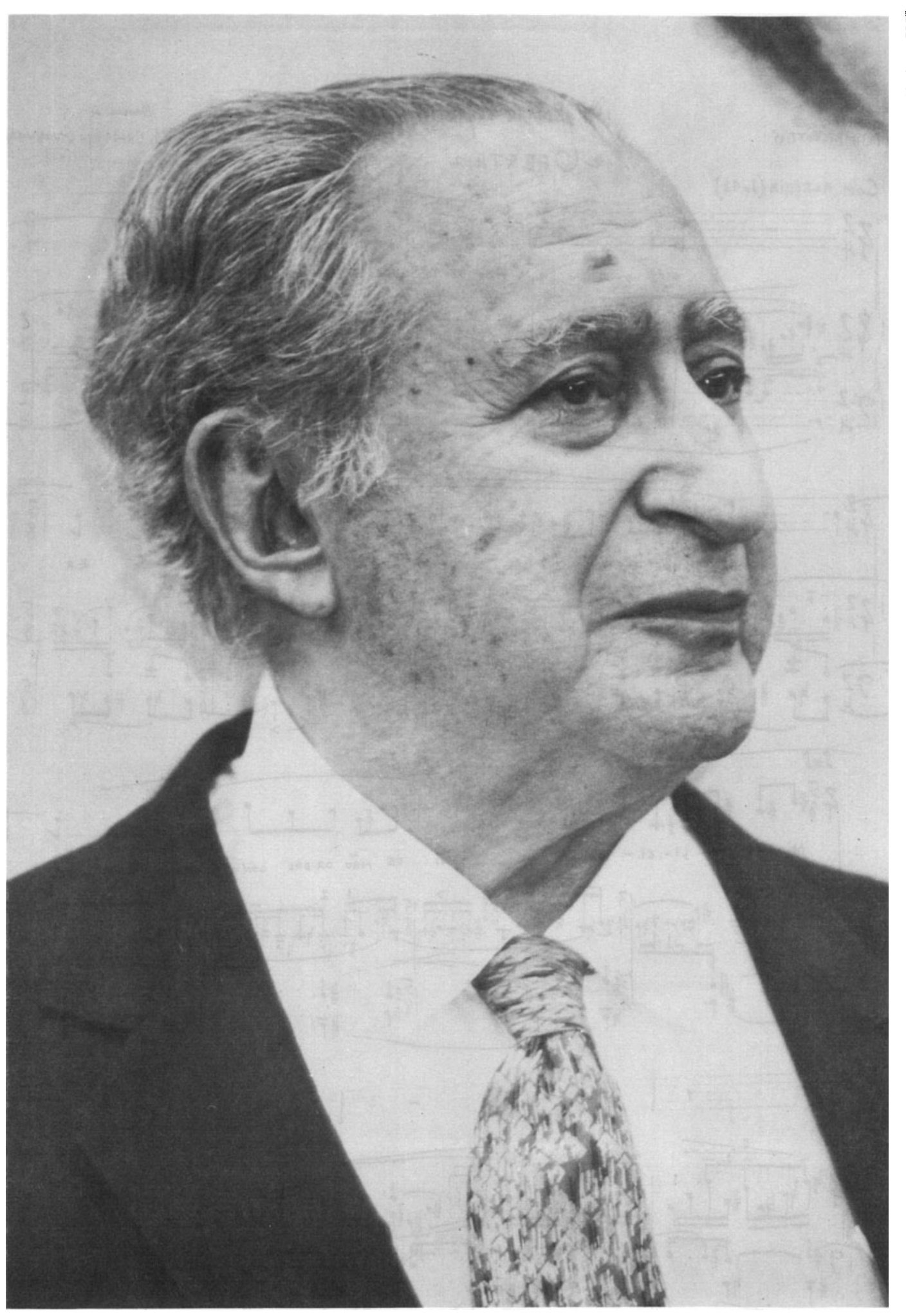

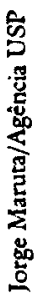

Camargo Guarnieri 1907-1993

ESTUDOS AVANÇADOS 6(16), 1992 
Pasin $\mu$

TENATA PALlotrivi

Com Alegrin (dea2)

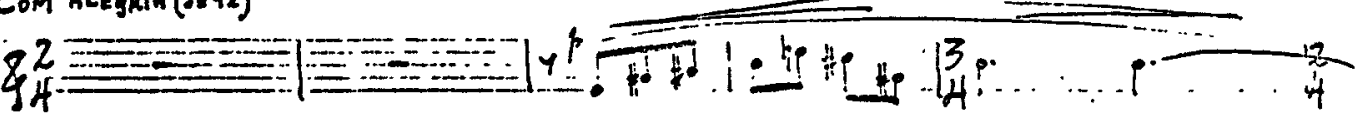

Hei oe te. dar sempre um pou - - co

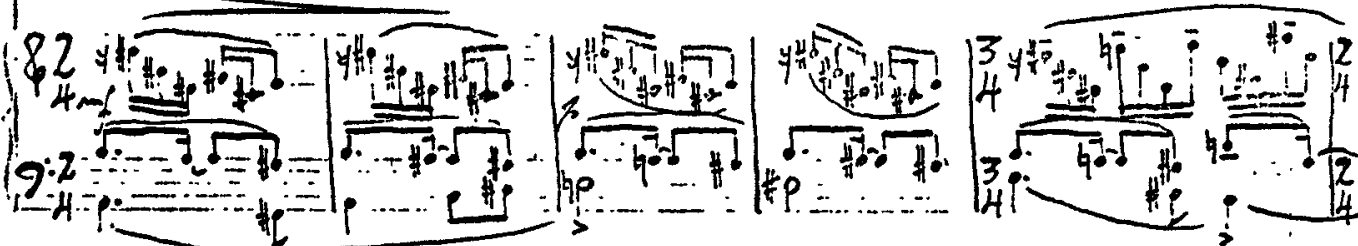
- t

M. Camirrgo Guarmikai

anseans - 1t-t

\section{8}

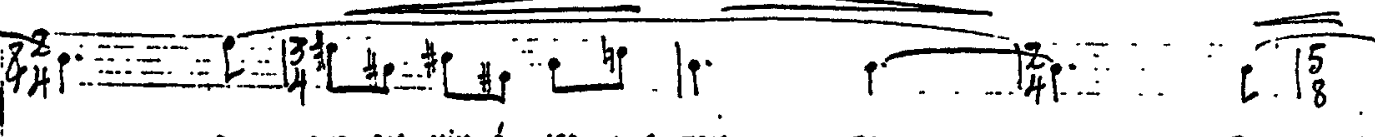

D. que EM miM É SER CON-TEN - - TE

E

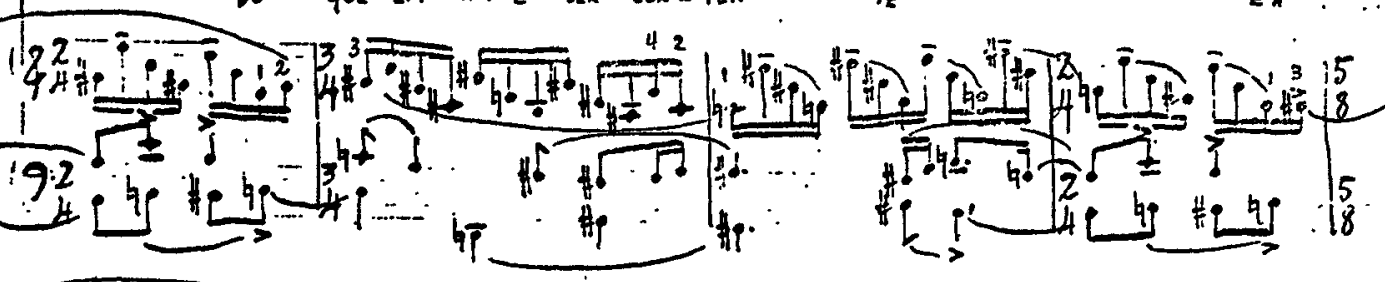

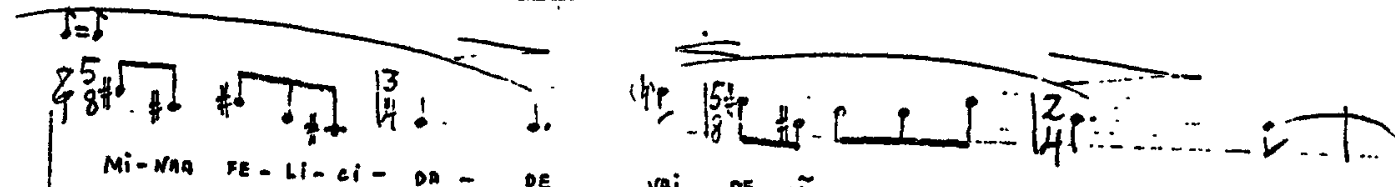

Mi-NAA TE-LI-Ci- DA - DE VAI DE MÄO OA-DAS GON- - Ti - - PO.

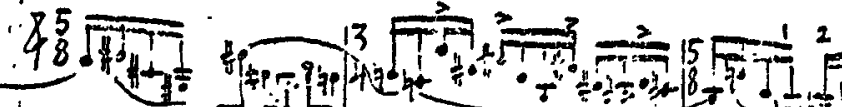

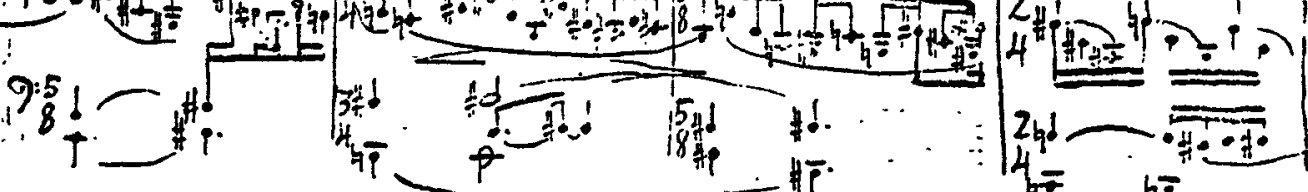

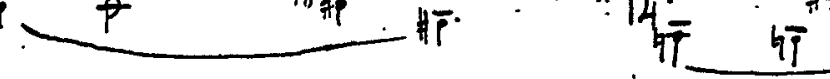

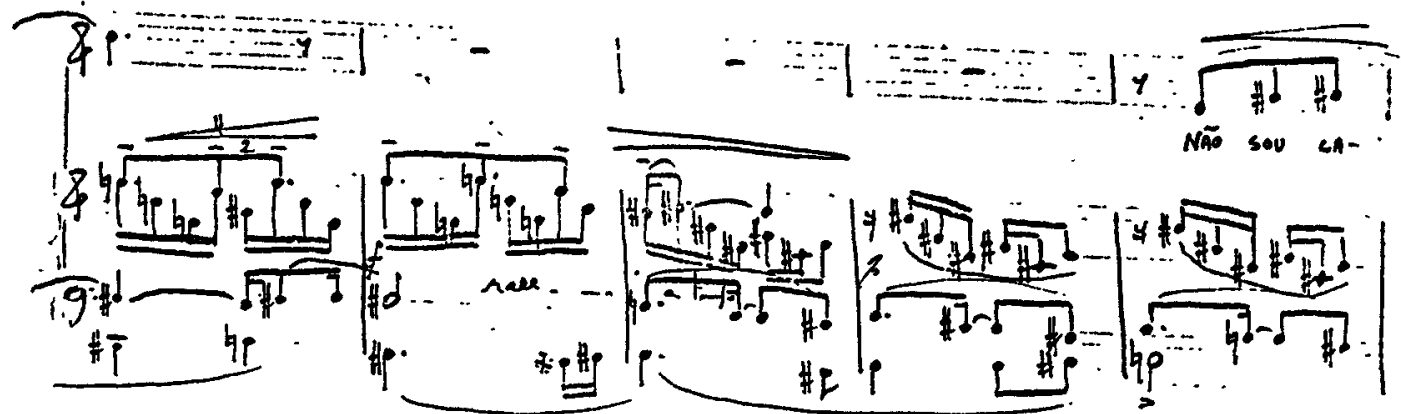




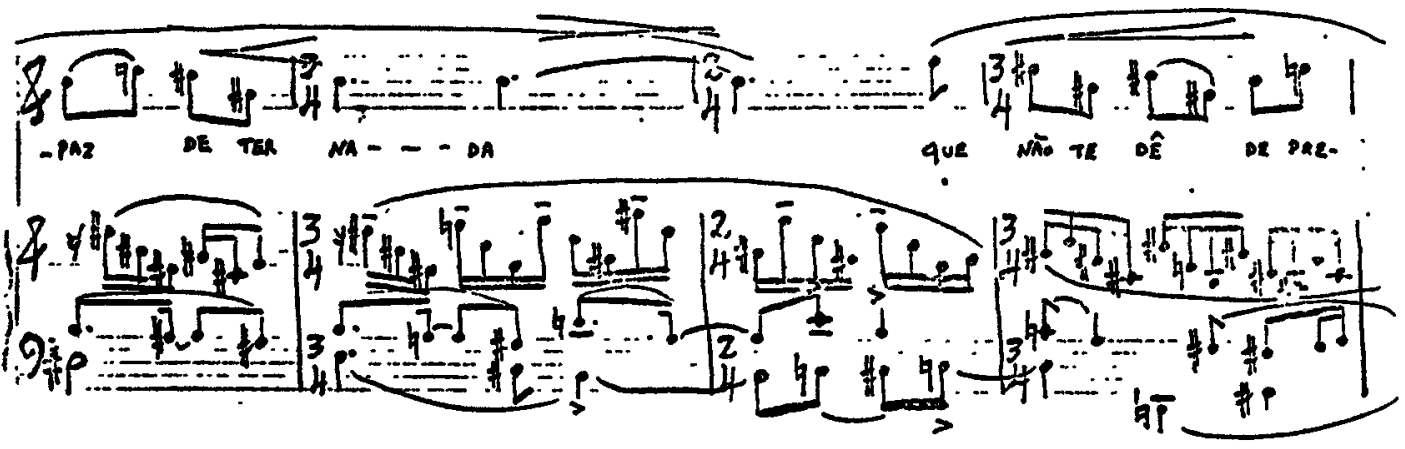

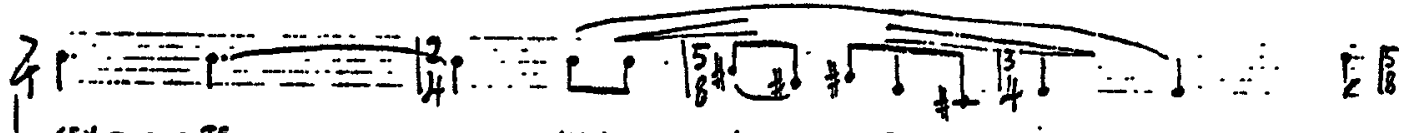

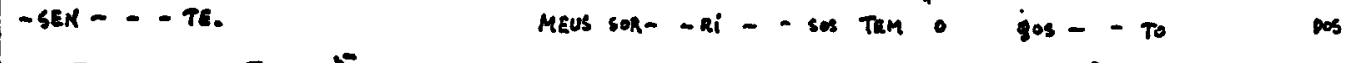

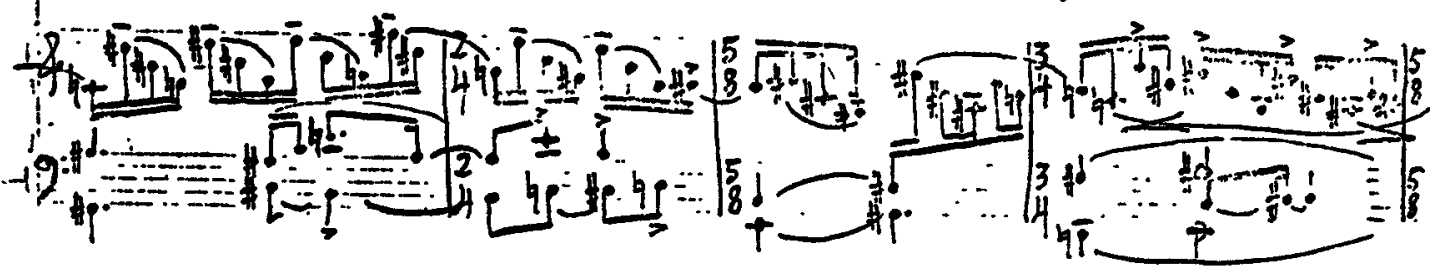

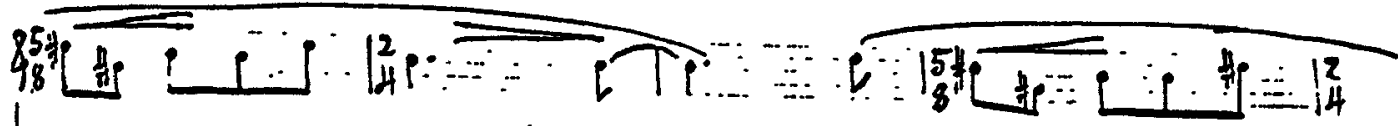

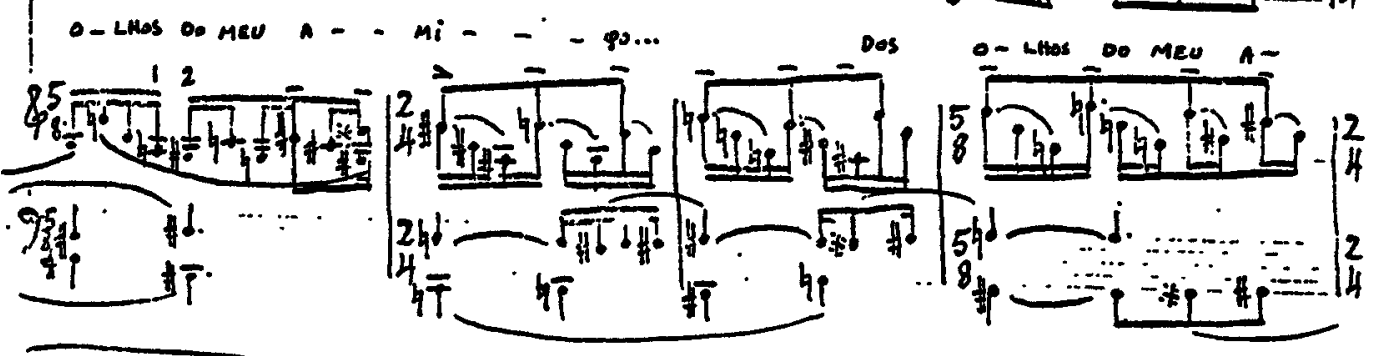

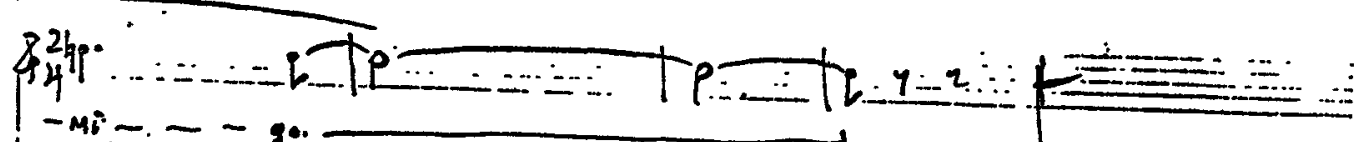

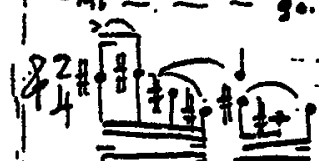

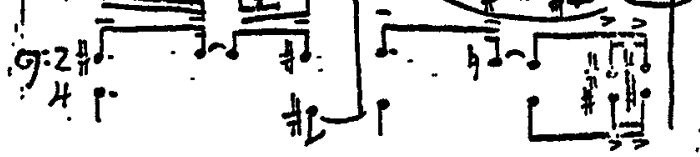

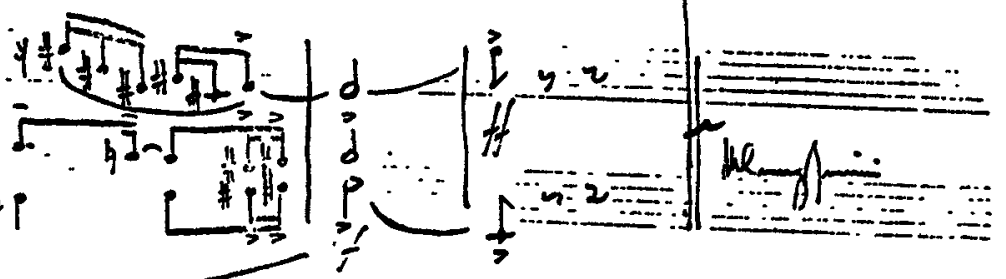



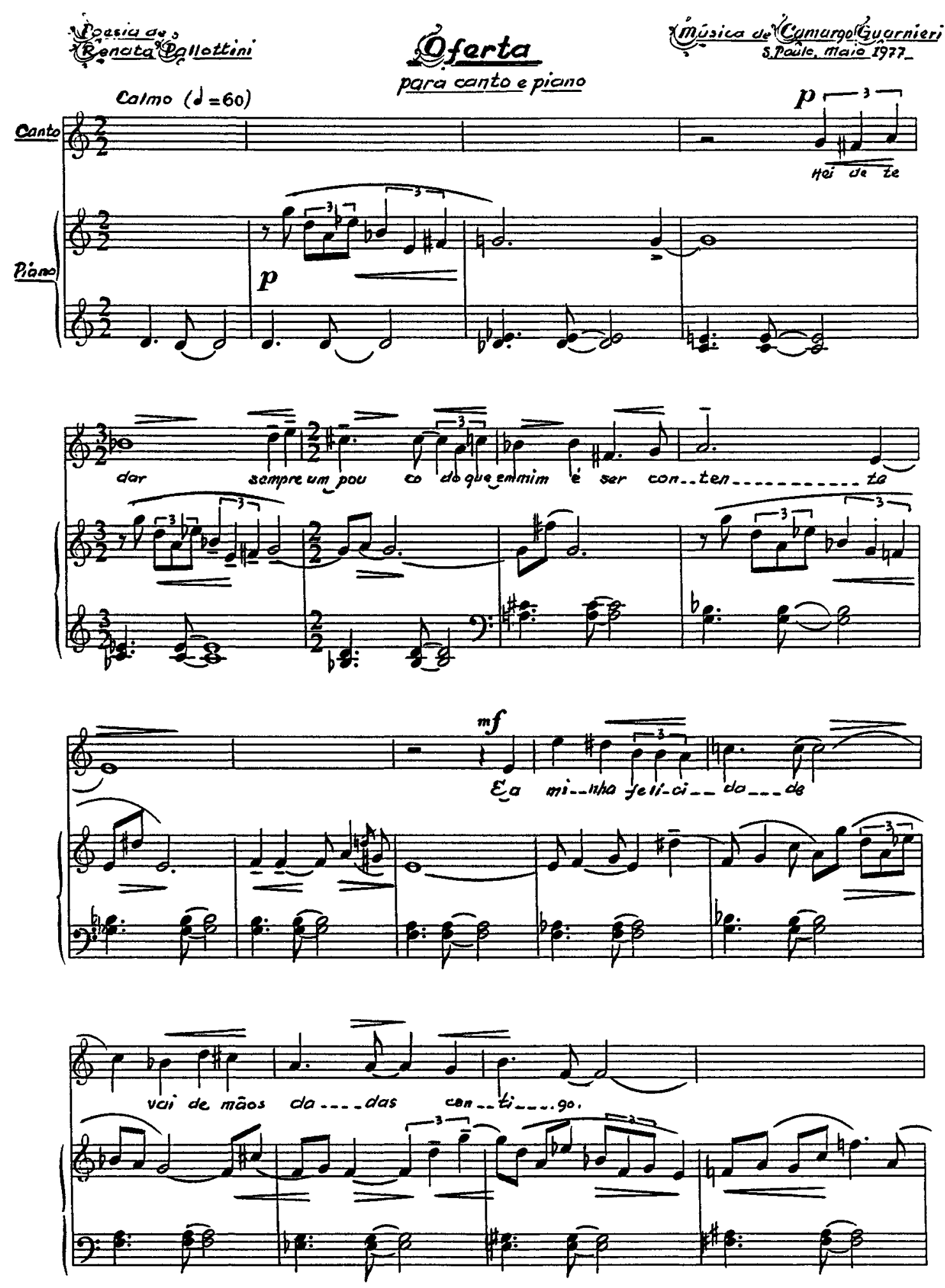

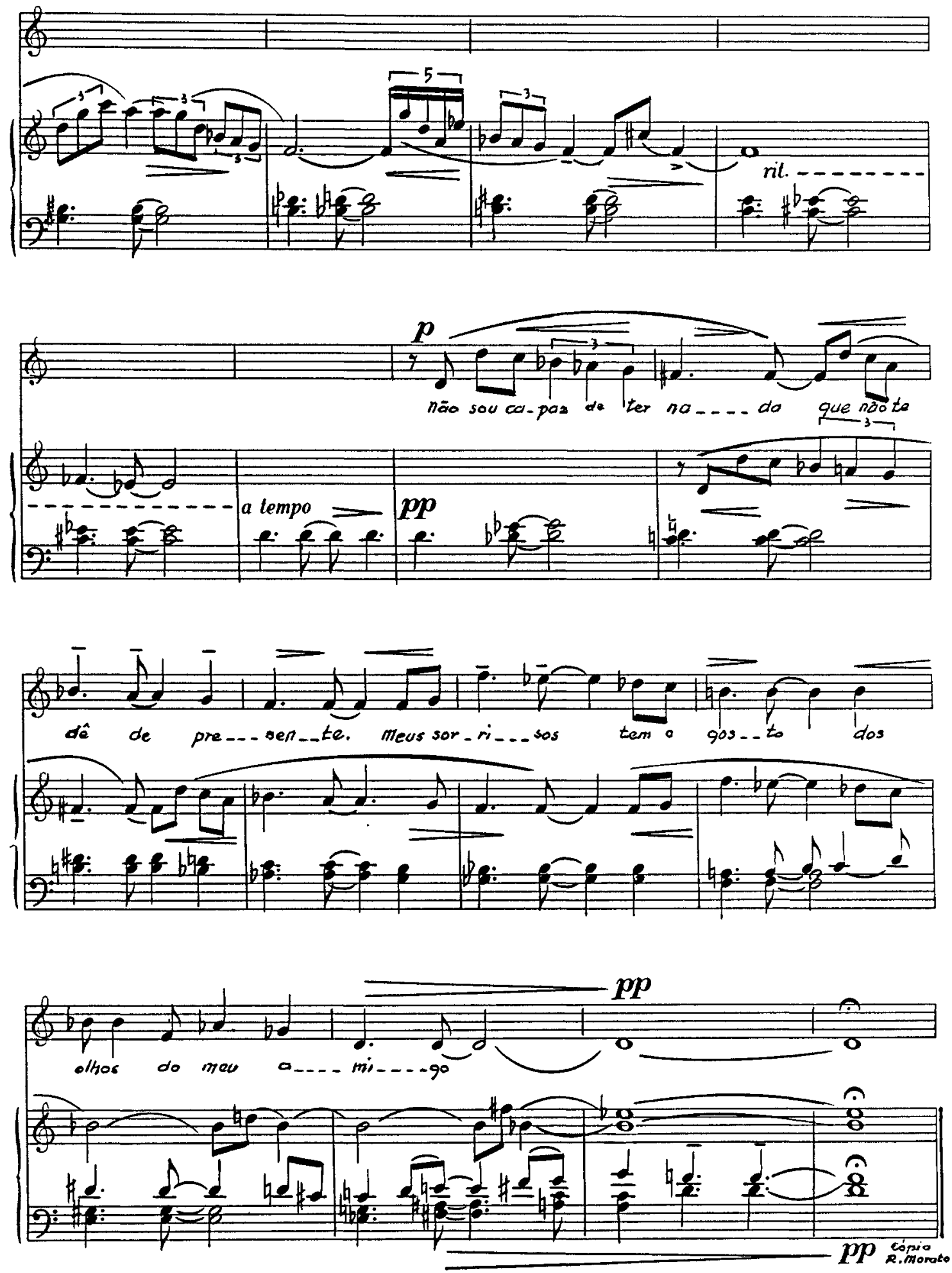